\title{
CORRESPONDENCE
}

\section{CONJUNCTIVAL LESIONS}

To the Editorial Committee of the BRITISH JouRnAl OF OPHTHALMOLOGY

SirS,-Your attention is invited to a case report on "Conjunctival Pockets", by Dr. S. Ayoub of Egypt (Brit.J. Ophthal., 1963, 47, 126). The author is to be complimented on drawing attention to a condition which, though not uncommon, is seldom mentioned in the literature, and then under various names.

Herbert (1901), working in South India, used the term 'conjunctival bridge'. The condition had been noted by Harlan and de Schweinitz (1896) and fully described by Schapringer (1899), but because it was mistakenly thought to be a congenital anomaly, was mentioned by Duke-Elder (1938) in the section on developmental and congenital anomalies of the conjunctiva as "Epitarsus".

Singh and Grover (1960), working in the rural areas of Northern India, described with seven black-and-white and seven kodachrome pictures a variety of cases of epitarsus and allied post-inflammatory conjunctival adhesions and scarring. They gave the prevalence of epitarsus as roughly 1 in 200 persons in the vast regions of the world where living standards are poor and trachoma is endemic, and described its pathogenesis, clinical manifestations, differential diagnosis (especially from trachomatous scarring of the conjunctiva), and treatment. They urged that the text-books of ophthalmology should mention this condition in discussing the complications or sequelae of neglected acute conjunctivitis.

$$
\begin{gathered}
\text { Yours faithfully, } \\
\text { SATNAM SINGH. } \\
\text { W.H.O. Medical Officer for Trachoma Control in Thailand. }
\end{gathered}
$$

3957/7 Chakri Road,

Korat,

Thailand.

May 12, 1963.

\section{REFERENCES}

DUKE-ELDER, S. (1938). “Text-book of Ophthalmology", vol. 2, p. 1275. Kimpton, London. Harlan, G. C., and DE SchweINITZ, G. E. (1896). Trans. Amer. ophthal. Soc., 7, 418, 422. HERBERT, H. (1901). Trans. ophthal. Soc. U.K., 21, 16.

SCHAPRINGER, A. (1899). Z. Augenheilk., 2, 41.

SingH, S., and Grover, A. D. (1960). A.M.A. Arch. Ophthal., 63, 503.

\section{BOOK REVIEWS}

Light. By R. W. Ditchburn. 2nd edition, 1963. Pp. 833, numerous figs, bibls. Blackie, London. (75s.)

This text, designed for the advanced physics student, presents a comprehensive survey of all the important aspects of physical and geometrical optics. Much of the detail will be beyond the requirements of the ophthalmologist, but it is most valuable to have in one volume such a detailed and clear exposition of the scientific basis of much of our practice. It is fascinating to see how so much of the work devoted to physical optics takes us into the heart of present-day theory of the nature of matter and its inter-relationship with radiation. The classical geometrical optics is, however, by no means neglected, and 